\title{
Gasoline Consumption and Cities Revisited: What Have We Learnt?
}

\author{
Peter Newman' ${ }^{1}$ Jeff Kenworthy ${ }^{1,2}$ \\ ${ }^{1}$ Curtin University Sustainability Policy (CUSP) Institute, School of Design and the Built Environment, Curtin University, Perth, \\ Australia \\ ${ }^{2}$ Frankfurt University of Applied Sciences, Frankfurt am Main, Germany \\ Email:p.newman@curtin.edu.au
}

How to cite this paper: Newman, P., \& Kenworthy, J. (2021). Gasoline Consumption and Cities Revisited: What Have We Learnt? Current Urban Studies, 9, 532-553. https://doi.org/10.4236/cus.2021.93032

Received: August 5, 2021

Accepted: September 6, 2021

Published: September 9, 2021

Copyright (c) 2021 by author(s) and Scientific Research Publishing Inc. This work is licensed under the Creative Commons Attribution International License (CC BY 4.0).

http://creativecommons.org/licenses/by/4.0/ (c) (i) Open Access

\begin{abstract}
This article provides a personal reflection 30 years after we created the concept of automobile dependence. The paper entitled "Gasoline Consumption and Cities: A Comparison of US Cities with a Global Survey and Its Implications" and an associated book "Cities and Automobile Dependence" stirred up transport planning, especially in the US. We examine the criticisms, this evoked at the time within the perspective of what has happened in cities since then. Key policy prescriptions of re-urbanizing cities and prioritizing transit, walking and cycling, have been largely mainstreamed, though not without some painful changes in professional practice such as road capacity increases being seen as the only solution to traffic. Urban planning and transport policies adopted in innumerable cities worldwide have moved to reduce automobile dependence, though academic and policy debate continues. The future is likely to continue this debate, especially over autonomous cars where there will remain a fundamental need to keep cities on a path of reduced automobile dependence by ensuring that hard-won principles of reurbanization of corridors, integrated with new transit alternatives and walkability at precincts/stations, are given the highest priority.
\end{abstract}

\section{Keywords}

Automobile Dependence, Gasoline Consumption, Transit, Walkability, Density

\section{Introduction}

In 1989 we published "Gasoline Consumption and Cities: A Comparison of US Cities with a Global Survey and Its Implications" (Newman \& Kenworthy, 1989a) along with a parallel book "Cities and Automobile Dependence: An International 
Sourcebook" (Newman \& Kenworthy, 1989b). The article and book were based on ten years of data collection, personally derived from 32 cities by two Australians who liked to travel and were prepared to derive a standardized urban data system to compare cities across the world. We unleashed something that we had not quite expected and have followed the academic and professional argument ever since. This paper tries to see what we have learned and what it can mean for the future.

We showed in 1989 that US cities were significantly higher in their gasoline consumption per capita than other developed cities and that it did not seem to be related to income and fuel prices as much as land use and priorities given to non-automobile infrastructure. There were very significant responses that were highly personal as outlined below and which certainly went beyond anything we had contemplated (Gordon \& Richardson, 1989). Over the years a debate has followed but seems to be largely resolved now as will be outlined below.

We have continued to work in this area and have published papers and a trilogy of books on the topic and related issues (Newman \& Kenworthy, 1989a; 1999; 2015); but we no longer maintain the substantial database on global cities which requires significant resources and a great deal more youthful energy. It would be good if it was restarted as such global data are not being produced on a standardized and transparent basis though the Demographia database (Cox \& Pavletich, 2020), on density is now coming closer to providing the land use trends; however the infrastructure, transport and energy trends are not collected. Whilst it is very difficult and incredibly time-consuming to collect data on a wide variety of cities around the world, if one is dedicated enough and is prepared to invest a lot of time in collecting the data (much of which must be obtained through detailed conversations with people in each city because it is not generally published), it is possible to come up with acceptable data sets that are comparing apples and apples. Our international comparisons have spanned over a 40 -year history now and this research, its methodologies and different phases have been published in some detail in Kenworthy (2017a). The Millennium Cities Database for Sustainable Transportation (Kenworthy \& Laube, 2001) was the largest compilation from this work.

After 30 years we felt the need to reflect on the 1989 research and see where we are now in comparison to that time. Thus, this paper will revisit the reaction to our research, look at some data trends, examine some better understandings that perhaps we now have, including our new Theory of Urban Fabrics, and briefly suggest some key priorities we may need to follow in our cities as we plan the next thirty years with issues like autonomous vehicles and the need for Net Zero Cities in the age of climate change.

\section{Reactions to "Gasoline Consumption and Cities"}

The research we did showed many factors were related to automobile dependence but the main interest in the article was about how automobiles and trans- 


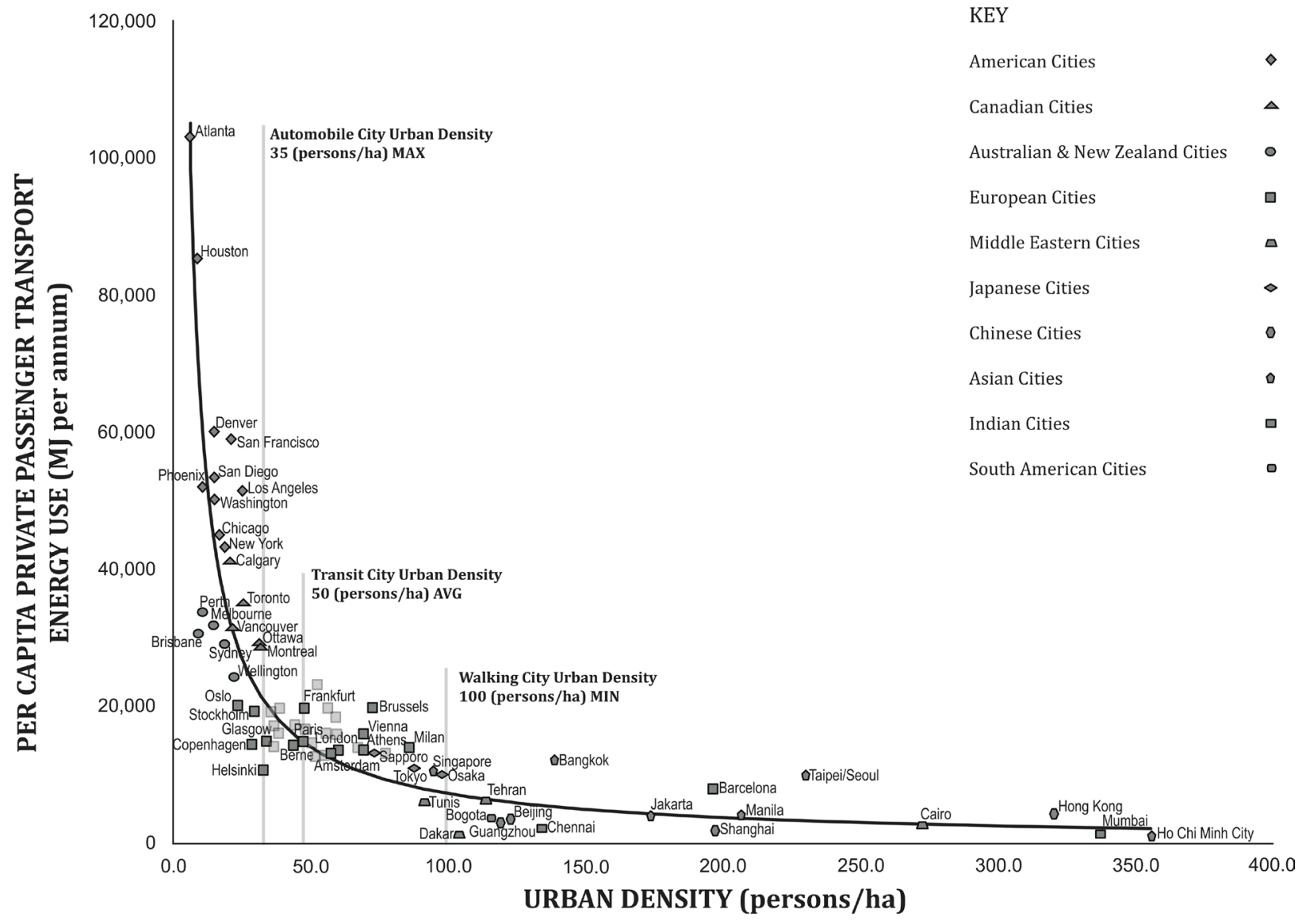

Source: Newman and Kenworthy (2015: p. 25).

Figure 1. Private passenger transport fuel use per capita vs urban density in 73 global cities. 
A complete description of the history of this global cities-research covering four decades and the evolution of Figure 1, can be found in Kenworthy (2017a).

The two main conclusions of the research work in 1989 were summarized as the need to: 1) Reorient transport priorities, and 2) Re-urbanize our cities.

Apart from the strong reactions explained below, even the focus on transport energy instead of vehicle miles (kilometres) travelled was criticised. It is therefore important to understand that gasoline use was a focus of our research because after the oil shocks of 1973/4 and the subsequent Iranian oil crisis in 1979, much academic and policy attention was paid to how cities could become less consumptive in oil in the transportation sector and thus reduce their vulnerability to disruptive events in the Middle East. Around this period we received significant funding from the National Energy Research Development and Demonstration Council of Australia for research on transport energy use in cities. What no one had systematically done by the 1980s, nor has anyone repeated since, was to work out and compare what cities around the world consume in running their passenger transportation systems and to explore macro-scale reasons for these differences.

The immediate reaction to the article by Gordon and Richardson in 1989 was titled "Gasoline Consumption and Cities_A Reply" and included the following, amongst many other strongly worded paragraphs:

"NK have written a troubling paper. Their distortions are not innocent, because the uninformed may use them as ammunition to support expensive plans for a central-city revitalization and rail-transit projects or stringent land use controls in a futile attempt to enforce urban compactness. Perhaps NK would be well advised to seek another planet, preferably unpopulated, where they can build their compact cities from scratch with solar-powered transit." (pages 342, 344, 345)

Given the widespread growth in central city residential development particularly in auto-dependent American and Australian cities, the extensive efforts to pedestrianize or at least traffic calm central cities and the dynamic growth of urban rail in cities around the world (Newman, Kenworthy, \& Glazebrook, 2013), it is difficult to see today what is wrong with "central-city revitalization and rail transit" or even "land use controls". There has of course been a cultural shift in the US and Australian planning systems as well as a demand for more urban and less suburban opportunities than we were able to envisage in 1989. The concept of "automobile dependence", which we introduced in the 1989 article and book, has become a part of the language of planning and our responses to the problem, especially "urban compactness" that were so ridiculed at the time, have become basic pillars in most future thinking about mobility and planning in cities (see Schiller and Kenworthy (2018) and Newman and Kenworthy (2015) for many examples.

There were a lot of responses to the paper and the book at the time that tried 
to challenge the analysis and which could not see any need to change the American way of city building (Wachs \& Crawford, 1991; Gomez-Ibanez, 1991). It was not just a rational debate however. We were visited in Perth by a prominent transport journal editor who just wanted to tell us that he would never publish anything we wrote as he was "a highway man". Throughout this era, when we spoke publicly around the world, there was a huge division between traffic engineering and urban planning. We never found a single engineer who would break ranks with their standard approach that the solution to congestion was to increase road capacity. Three were discovered in the 1990's in Portland, Copenhagen and Sydney! Today they are everywhere though this notion is still alive, particularly the idea that fuel will be saved when stop-start driving is reduced. This had become a big part of benefit-cost ratios for new highway projects and was deconstructed by us and used by the US EPA in a court case that was won and led to much bigger considerations of land use (Newman \& Kenworthy, 1988). The work is conveniently forgotten today in some places and projects despite the notion of "induced traffic" being widely understood.

The work that we presented in terms of land use and transport, has since been called the "Newman-Kenworthy Hypothesis" by Reid Ewing who has stated (Ewing et al., 2017) that the book "Cities and Automobile Dependence (1989) is one of the most influential planning books of all time". The hypothesis has been tested over and over by many people doing much more modelling than we were ever capable of doing. Ewing and Cervero (2017) summarized much of the literature in "Does Compact Development Make People Drive Less? The Answer Is Yes".

The idea has often stuck that we only talk about density in our work (stated by Ewing in the article above) but we always had a range of parameters to describe automobile dependence that relate to urban design and walkability in cities and have written a lot on these topics over the years (e.g. recent work like Schiller and Kenworthy, 2018, especially Chapter 6) and Matan and Newman (2016).

More particularly, in our last book in the trilogy (Newman \& Kenworthy, 2015), and in a paper we did present the results of some modelling that used our data from 1960 to 2005 and this summarises our work over 30 years. We re-examined the question of what most causes transport patterns and in McIntosh et al. (2014) we concluded:

"Structural equation modelling ${ }^{1}$ is employed to address causation and understand the direct and indirect effects of selected parameters on per capita vehicle kilometres travelled (VKT). Findings suggest that, while location effects are important, transit service levels and urban density play a significant part in determining urban car use per capita, and causality does flow from these factors towards a city's levels of private vehicle travel as well as

${ }^{1}$ SEM involves modelling relationships as a system of equations, taking into account the "back and forth" among related variables such that the estimation of a variable of interest is free from bias. 


\section{the level of the provision of road capacity." (p. 95)}

So, automobile dependence is derived from an urban system that is shaped by a combination of transit service, urban density and the level of provision of road capacity. The concept of reducing this, for multiple benefits, was clearly on the agenda for most of the past 30 years but what we do about it in our cities certainly has differed around the world. In the US this has focussed on Transit Oriented Development, New Urbanism and Smart Growth (Calthorpe, 1993; Duany, Plater-Zyberk, \& Speck, 2001; Duany, Speck, \& Lydon, 2009) and in Australia, Europe and Asia it has been mostly Sustainable Cities (Houghton \& Hunter, 1994). Resilient Cities has more recently been the chosen title and Smart Cities though this is rejected by the UN who say in the Sustainable Development Goal number 11 that we need "inclusive, safe, resilient and sustainable cities". In none of these framings is automobile dependence seen as a good thing.

\section{The Cultural Shift}

Whilst the scientific assessment and planning debates have been going on it would appear that many people have moved with their feet, literally, as urban regeneration of older areas took off and transport priorities have been moving more and more towards other modes. This cultural shift is reflected in the titles of our three main books which as stated above have become like a trilogy: the first (Newman \& Kenworthy, 1989b) is where we introduced the empire of automobile dependence and how it needed to be fought; the second (Newman \& Kenworthy, 1999) is where the war was being conducted and some battles were being won; and the third (Newman \& Kenworthy, 2015) is where the war is over but many battles remain. We can confidently say that "cities are moving beyond carbased planning" as in the sub-title of "The End of Automobile Dependence".

There are plenty of cities that are now pushing this agenda further, for example, Elks (2019) reports predictions that European cities such as Oslo and Amsterdam may be the first cities to go "car-free", followed by some French cities. She writes: "Experts on cities agreed urban planners were moving away from private cars." A Guardian editorial (27 ${ }^{\text {th }}$ December, 2019) on "Car Culture: Change is Coming" reflects on a Victoria and Albert Museum exhibition on the automobile (Morrow, 2019); the question is asked "could 21st-century transport be more radically reconfigured in such a way as to reduce our dependence on private cars?"

In the USA, some of the mostly highly auto-dependent cities are demonstrating ground-breaking efforts to forge a new, less car-dependent paradigm with the defined City of Los Angeles (not all of LA unfortunately) perhaps being the most spectacular turn-around (Sloane, 2017; Darchen, 2016; Bullen, 2009). A recent example of a new development is found in Tempe, Arizona where a 16acre (6.5 ha) new development involving 636 one to three bedroom apartments and a retail centre will be largely car-free and based on place-making principles 
(Steuteville, 2019). Given the data available and assuming a conservative 1.5 persons per apartment, the urban density on the site would be around 147 per ha or well into the range of densities normally associated with walking cities (Newman et al., 2016). The developer states: "This is a game changer... Especially being built in a region that has a long history of auto-dominated development patterns. This project will prove it is time for cities to rethink parking requirements and allow the developers to respond to the market demand for car-light and car-free living. We have been waiting for a project like this for 20 years!"

Cities that are relatively well known internationally for their efforts to reduce automobile dependence include Perth in Western Australia (which since the early 1990s has been building new urban rail lines into low density car-based corridors-Newman, 2021). Vancouver, British Columbia is another example, with its rapidly expanding rail system and world-renowned walkable neighbourhoods. Portland, Oregon is well-known for transformation of its inner area into a more walkable and livable environment and rapid expansion of light rail transit since the mid-1980s. Freiburg-im-Breisgau, Germany is notable for dense transit-oriented development linked to light rail throughout the metro area and for being one of the world's greenest, most attractive walkable and bicycle-oriented cities (Newman \& Kenworthy, 2015; Schiller \& Kenworthy, 2018). Large Chinese cities throughout the country, such as Beijing, Shanghai and Guangzhou, after some decades of pro-automobile policies, are also turning a corner and building more and more extensive metro systems, reinvigorating bike travel and charging for the right to own and use a car (Gao \& Newman, 2018; Kenworthy, 2017b; Gao \& Kenworthy, 2017; Gao et al., 2018). Many Indian metro areas are also seeing a massive increase in the building of metro systems (Newman, Kenworthy, \& Glazebrook, 2013), sometimes with innovative financing (Sharma \& Newman, 2018).

Of course the battles are still raging over such changes and will no doubt continue and we all know only too well how a fight back may happen and reverse all the gains. The mainstreaming process to replace old manuals, models and tools needs to catch up with the innovations that are now being demonstrated to meet this change in culture (Newman \& Kenworthy, 2015, chapters 5 and 6 outline this transition). Some good examples of what is needed are Donald Shoup's deconstruction of parking manuals (Shoup, 2005) and Los Angeles City discarding of Levels of Service manuals on roads as well as new funding models (Sharma \& Newman, 2020).

Why density has become more popular in culture, in broader issues such as sustainability (Newman, 2017) and is more clearly used in planning as a tool to overcome automobile dependence, is that it is commonsense that the more people near a transit stop or within a short walk of a city centre, the more opportunities there are to not use a car. As many people have become aware of the transport disadvantages in living on the fringe compared to living in reurbanized areas, the cultural advantages of urbanism have grown (Leinberger, 2007; Leinber- 
ger \& Lynch, 2014). The economic impacts of reurbanzing cities compared to putting the same number of houses at low density on the urban fringe has become clearer though still controversial (Ewing and Hamidi, 2017; Trubka et al., 2010a, 2010b, 2010c). The health impacts of urban sprawl have been heavily pushed by people examining health and active transport (eg, Handy, 2002; Handy et al., 2002). Lancet did a three-part series on health and urban design in 2016 strongly pushing density ${ }^{2}$. Buehler et al. (2020) in a detailed analysis of the US National Household Travel Surveys from 2001 to 2017 also highlight the density factor: "National rates of daily walking rose slightly from 2001 to $2017 \ldots$ Walking and cycling were highest among well-educated persons, households with low car ownership, and residents of high density neighbourhoods." (p. 1)

\section{Data Trends}

The data we collected over this period to enable us to do such analyses have become easier than in the early days to some degree. To calculate urban density in a standardized way instead of just dividing population by a political area, we drew lines around city maps delineating urbanized areas and weighed the cutout paper to enable us to be sure of urbanized densities. This was not hi tech but it worked as political boundaries do not give anything useful for planning but their use remains a common fault in many published papers in this area. If a metropolitan area is defined politically with a lot of vacant, undeveloped land, the density so calculated will be artificially low and will not represent the actual density of the built form and thus it will not pick up the transport effects of this built form. This is why it is critical to obtain actual urbanised land. However, much of the transport data is harder to get due to confidentiality issues with private providers and a general diminution in governments' ability and willingness to service extra data requests that are not already part of the public record and much of our data fall into the latter category.

A critical need in ensuring that cities track in the right direction of reducing automobile dependence as outlined in this paper, is the availability of good, current urban data on the transport, mobility and land use characteristics of metropolitan areas worldwide. The perspectives provided by our research over the last more than 40 years have been very much dependent on long, difficult, poorly funded and therefore self-subsidized studies to build the global cities databases for different time periods. Urbanization is proceeding globally at a pace never seen before in human history, especially in the world's most populous countries such as India, China and Indonesia, as well as on the African and Latin American continents and other parts of Asia. As will be shown below, in 2021 we have only been able to extensively report data up to 2006 and some data beyond that up to about 2011; this is a deficiency that is hard to overcome but any process of data collection on complex entities like cities does require a great deal more resourcing than we have been able to attract. Without proper resourcing and the ${ }^{2}$ https://www.thelancet.com/series/urban-design. 
ability to train new people in the exacting task of comparative urban data collection over a much wider range of cities, this deficiency is unlikely to improve in the near future. It nevertheless remains a solvable challenge in the medium term if due recognition of its value can be gained.

The trends we have examined over forty-five years took a substantial turn around in the early part of this century towards a reduction in automobile dependence as outlined next. The phenomenon of "peak car" (Puentes \& Tomer, 2009; Newman \& Kenworthy, 2011) should have been predicted from our data as the global cities data showed that VKT per capita grew 42\% in 1960-70, 26\% in $1970-80$ and $23 \%$ in $1980-90$, but in the decade $1995-2005$ it grew a mere $5 \%$. The trend was towards zero or negative growth but none of the models predicted this because income growth, it was believed, would guarantee car ownership and car use growth and planners continued to say that people would buy space and shift to car dependent suburbs. But the data show that perspective turned around as cities changed in their spatial and transport priorities over the next 20 years. Indeed the growth in per capita car use decoupled from the growth in metropolitan GDP in a large number of wealthy cities around the world, as well as in some less wealthy ones. And between 1995 and 2005 a large sample of cities experienced significant percentage declines in the car kilometres driven to earn one real unit of GDP (Kenworthy, 2013; 2017b). The same phenomenon has occurred in the USA nationally and in a wide range of their cities (Kooshian \& Winkelman, 2011). Figure 2 depicts these changes, showing that in all except three of the cities, the amount of car travel required to earn a unit of GDP in real local currency (LCR), declined by up to $50 \%$, with most declining by $10 \%$ or more (only six cities declined by less than 10\%). The three cities that experienced some increase in this factor (mostly tiny) had low growth in metropolitan GDP over the decade due to economic factors, rather than large increases in car use. Subsequent research has shown that rapidly motorizing cities such as São Paulo have also declined in this factor (48\% between 1996 and 2011), while Taipei declined by $41 \%$ for cars and $11 \%$ for motorcycles from 1996 to 2006 for a combined decrease of $29 \%$ in private motorized travel per real local currency of GDP (Kenworthy, 2017b). Motorcycle travel in Taipei is especially important, unlike in all the other cities in Figure 2.

Perhaps the most significant data we collected (Newman \& Kenworthy, 2015) showed that firstly, density began to increase in most cities, reversing sustained earlier declines, and secondly, transport priorities in cities began to shift, particularly as the relative speed of rail transit to road vehicle transport became faster, as in Table 1. Table 1 shows that only US and Canadian cities had not quite reached the "peak" in the relative speed of the whole public transport system compared to average road traffic speed. The data show the American and Canadian cities teetering back and forth between about 0.54 and 0.56 , meaning that public transport as a system in North American cities was, in 2005-6, still 


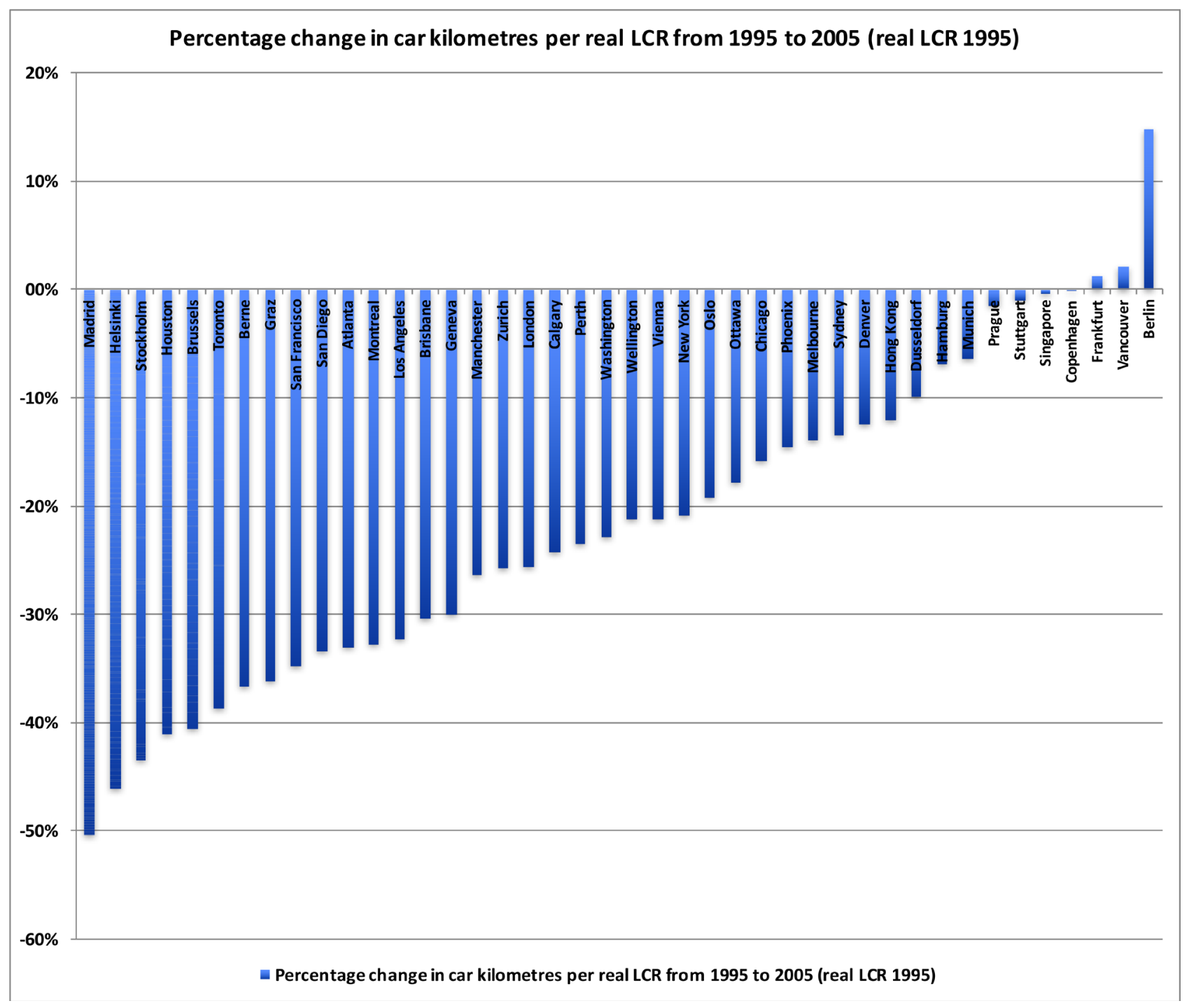

Figure 2. Percentage change in car kilometres travelled per unit of real GDP in forty-two cities (measured in real local currencies). Source Kenworthy (2017b).

little better than half as fast as cars. However, in Asian, European and Australian cities, there has been a relatively steady and progressive improvement in public transport system speed compared to cars over the last 45 years. In these cities, public transport overall was, by 2005 , between $75 \%$ to $90 \%$ as fast as cars.

Any visitors to these latter cities can appreciate the speed benefits of public transport and not needing to worry about a car to get them where they are wanting to go in a reasonable time. In the thirteen US cities we studied, by 2005 the highest speed ratio, however, was only 0.69 , shared by New York and Atlanta, with Washington not far behind (0.64). However, many US cities such as Los Angeles, Phoenix, Portland and Houston with public transport speed ratios of only around 0.47 have been and are still building more and more light rail (and metro in the case of LA), to try to improve their public transport speed performance (Glazebrook \& Newman, 2018). 
Table 1. Relative speed of public transport to road speed and rail transit to road speed, 1960-2005.

\begin{tabular}{ccccccc}
\hline COMPARATIVE SPEEDS IN GLOBAL CITIES & 1960 & 1970 & 1980 & 1990 & 1995 & 2005 \\
\hline Ratio of overall public transport system speed to road speed & & & & & \\
\hline American cities & 0.46 & 0.48 & 0.55 & 0.50 & 0.55 & 0.54 \\
Canadian cities & 0.54 & 0.54 & 0.52 & 0.58 & 0.56 & 0.55 \\
Australian cities & 0.56 & 0.56 & 0.63 & 0.64 & 0.75 & 0.75 \\
European cities & 0.72 & 0.70 & 0.82 & 0.91 & 0.81 & 0.90 \\
Asian cities & - & 0.77 & 0.84 & 0.79 & 0.86 & 0.86 \\
Global average for all cities & 0.55 & 0.58 & 0.66 & 0.66 & 0.71 & 0.70 \\
\hline Ratio of metro/suburban rail speed to road speed & & & & & \\
\hline American cities & - & 0.93 & 0.99 & 0.89 & 0.96 & 0.95 \\
Canadian cities & - & - & 0.73 & 0.92 & 0.85 & 0.89 \\
Australian cities & 0.72 & 0.68 & 0.89 & 0.81 & 1.06 & 1.08 \\
European cities & 1.07 & 0.80 & 1.22 & 1.25 & 1.15 & 1.28 \\
Asian cities & - & 1.40 & 1.53 & 1.60 & 1.54 & 1.52
\end{tabular}

Source: Newman et al. (2013: p. 281).

Continuing this data into the 2010 s is not complete but many cities are showing increases in the journey-to-work time that are now beyond the 30-minute level of the Marchetti Travel Time Budget, a core guide we have always seen as the significant cut-off. For example, the US Census Bureau recently produced a major new report on journey-to-work travel times in the US, which show a steady increase from a nationwide average in 2006 of 25.0 minutes to an average in 2019 of 27.6 minutes (Burd, Burrows, \& McKenzie, 2021). Contributing to this increase are the metropolitan areas in 2019 that significantly exceed the 30-minute level, such as New York (37.7 minutes), Washington (35.6 minutes), San Francisco (35.2 minutes), Riverside-San Bernadino-Ontario (33.9 minutes) and Boston (32.6 minutes). These metro areas also reported that $22.7 \%, 18.3 \%, 19.4 \%$, $18.4 \%$ and $15.6 \%$ of commuters respectively, had journey-to-work travel times of 60 minutes or more.

Marchetti posited that cities have always been about 1 hour wide, regardless of the dominant travel mode and a daily travel time budget of around 65 to 70 minutes is the norm for all cities everywhere, of which the journey-to-work for many people is the major contributor (Marchetti, 1994). Like many US metropolitan areas, all the big cities in Australia crossed the 30-minute average time for the journey-to-work in the 2002-2010 period (BITRE, 2016). This explains why transit investment has dramatically increased with less priority on big highways in these cities (Gaynor et al., 2017). High capacity roads rapidly con- 
gest and ultimately provide little benefit in maintaining the travel time budget. If rail is provided and it is faster, the shift becomes inexorable towards more transit-oriented living and development.

We explained the trends to peak car use in the 2000s in terms of:

1) Density Increases...cities rather than suburbs are coming back in popularity for economic reasons (Glaeser, 2011).

2) Travel time benefits moving from cars to rail...sprawling cities are hitting the Marchetti wall (as outlined above).

3) Cultural change...especially with the Millennials (as shown by Florida, 2010, 2012a, 2012b, 2012c).

4) Urban space efficiencies in the knowledge economy.... people need face-toface contact after all and the new economy jobs are primarily in walkable locations (Leinberger, 2007; Leinberger \& Lynch, 2014; Kane, 2010).

These trends have been confirmed or assisted by a multitude of academics, transport and city planners from across the world including recent studies by us on Shanghai and Beijing which have also demonstrated "peak car" (Gao \& Newman, 2018; Gao, Newman, \& Kenworthy, 2020). The trends are also quite extensive in transit investment, especially in Asian cities which are moving rapidly to build more urban rail and with Asian Development Bank shifting their funding from $91 \%$ on roads to just $45 \%$ between 2010 and 2019 (ADB, 2019).

In our book The End of Automobile Dependence (Newman \& Kenworthy, 2015) we suggested that this trend to inner city regeneration which helps to drive the peak car phenomenon would not continue once the first wave of gentrification had happened; this now seems to have set in with new US data showing that wealthy inner areas are putting up the shutters (Florida, 2018). The only way to maintain the trend away from automobile dependence into a significant on-going movement, would be to create a new way of regenerating car dependent cities, especially the middle and outer suburbs that were built around the car and are ready for redevelopment. This may need new and better understandings than we had thirty years ago and indeed many in the New Urbanism movement have driven this agenda for some time (Calthorpe, 1993; Duany, Plater-Zyberk, \& Speck, 2001). We now call this priority the need for Transit Activated Corridors that can go deep into automobile dependent suburbs as well as regenerating middle and inner areas (Newman et al., 2021). It will need new technology transit to unlock the precinct regeneration along the corridors.

\section{Better Understandings}

The most significant insight we have had in the past few decades has been provided by a visiting planner from Finland who spent a year with us going through the past 30 years of his life as a planner in a small town, Kuopio, implementing what he called our "theory". This, we discovered, was how cities are shaped and can be reshaped by recognizing, respecting and regenerating their three different urban fabrics. We had always collected our urban land use on the central city 
(usually an historic area built before the era of trains and trams and therefore walking-based), the inner area (usually the area before World War 2, which was before the automobile-based era and which was strongly shaped by public transport), and the outer area (which, due to the later timing of its development, was determined by automobile-based priorities and planning paradigms). This understanding we had framed into relevant land use and transport policies, but with Leo Kosonen we created the Theory of Urban Fabrics (Newman, Kosonen, \& Kenworthy, 2016). In this theory the Walking City, the Transit City and the Automobile City are part of all cities as shown in Figure 3 and they each need to be planned and managed differently. Of course, the respective proportions of each fabric varies widely from cities such as Atlanta where automobile city fabric is ubiquitous, to cities such as Berlin or Paris where transit city fabrics (and walking city fabrics) are widespread and Venice, which is virtually one hundred percent walking city fabric.

Based on the Marchetti Travel Time Budget we defined the three urban fabrics and the key characteristics in Table 2.

We have now been able to collect data to provide some further substance to the environmental qualities with a full urban metabolism of Perth by urban fabric (Thomson \& Newman, 2018), as well as showing how the theory can be applied to new transit technology and a framework of new urban design approaches (Newman et al., 2019b).

Perhaps the deeper level of understanding about this theory is how it seriously challenges the paradigm of planning developed from the Modernist agenda of Le Corbusier and the Congrès Internationaux d'Architecture Moderne (CIAM),

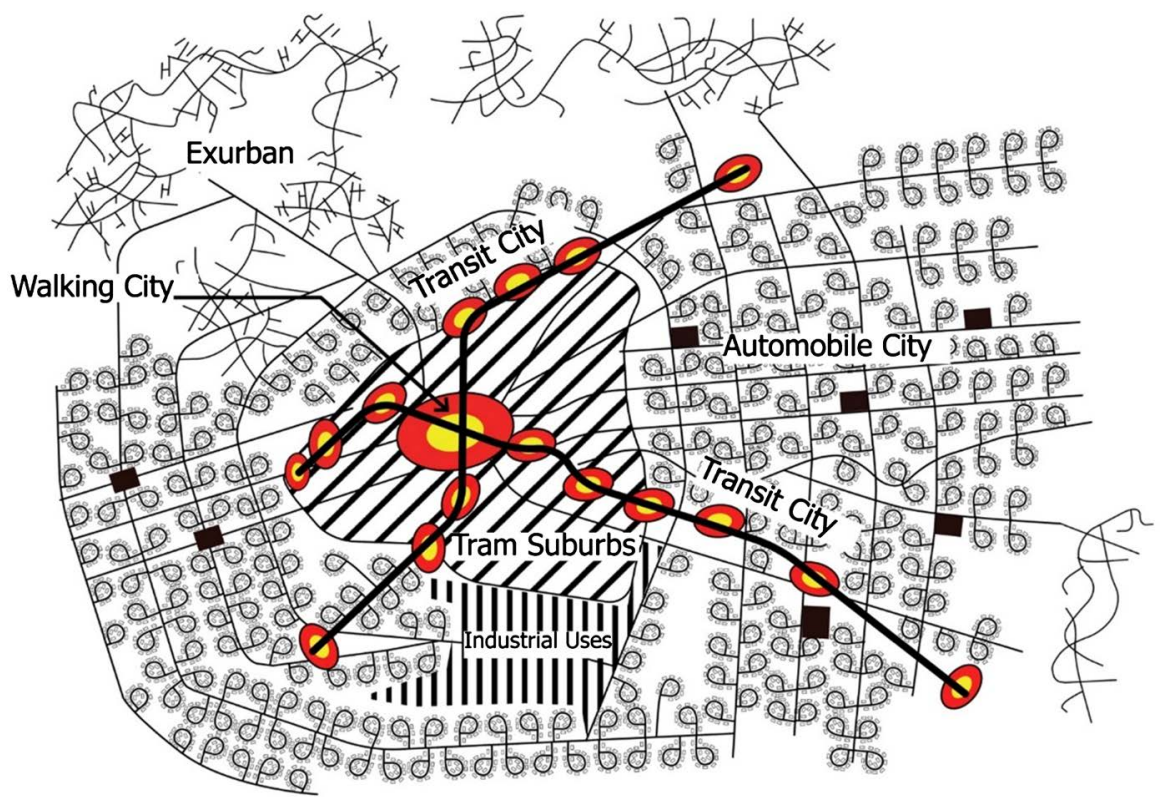

Source: Newman et al. (2016).

Figure 3. The Theory of Urban Fabrics with a variety of fabrics created by different transport modes. 
Table 2. Fabric qualities across the urban fabric elements.

\begin{tabular}{|c|c|c|c|}
\hline Urban Fabric Element & Walking City & Transit City & Automobile City \\
\hline \multicolumn{4}{|l|}{ 1. Urban form qualities } \\
\hline - Density & High & Medium & Low \\
\hline - $\operatorname{Mix}$ & High & Medium & Low \\
\hline \multicolumn{4}{|l|}{ 2. Transport qualities } \\
\hline - Car ownership & Low & Medium & High \\
\hline - Level of service (l.o.s) & High l.o.s for pedestrians & High l.o.s. for transit users & High l.o.s. for car users \\
\hline - Transport activity & High ped activity & High transit activity & High car activity \\
\hline \multicolumn{4}{|l|}{ 3. Economic qualities } \\
\hline - Infrastructure costs per capita & Low-Medium & Medium-Low & High \\
\hline - Gross domestic product per capita & High & Medium & Low \\
\hline - Labour intensity & High & Medium & Low \\
\hline \multicolumn{4}{|l|}{ 4. Social qualities } \\
\hline - Difference between rich and poor & Low & Medium & High \\
\hline - Ability to help car-less & High & Medium & Low \\
\hline - Health due to walking & High & Medium & Low \\
\hline - Social capital & High & Medium & Low \\
\hline - Personal security & Variable & Variable & Variable \\
\hline - Traffic fatalities & Low & Low & Medium to High \\
\hline \multicolumn{4}{|l|}{ 5. Environmental qualities } \\
\hline - Greenhouse gases and oil per capita & Low & Medium & High \\
\hline - Waste per capita (buildings, households) & Low & Medium & High \\
\hline - Footprint per capita & Low & Medium & High \\
\hline
\end{tabular}

Source: Newman et al., (2016).

which became so powerful over the past 70 years of urban growth and development (Curl, 2018). This approach saw only one kind of urban fabric, the Automobile City with all its new systems that cleaned out the old fabric and started again. Only by seeing the civility, livability and sustainability of Walking City and Transit City Fabric and the need for them to be respected can urban populations avoid the predations of some transport planners who saw the need to clean up cities. The battles between Robert Moses with his freeway plans and Jane Jacobs with her understanding of neighbourhoods, density, mixed land use and eyes on the street (National Trust for Historic Preservation, 2016), began to make more sense as we understood the need to respect each phase of urban development in the history of cities. This was confirmed by working for a number of years with Jan Gehl and seeing how he guided city governments in bringing life 
back to central cities by respecting their walkability (Gehl, 2010; Matan \& Newman, 2018).

The new urban agenda can then be seen as one where walkability is the main priority for Walking City Fabric (like the work of Jan Gehl, 2010), transit can be rebuilt or strengthened in Transit City Fabric with obvious immediate benefits (as in the City of Los Angeles and Vancouver, British Columbia) and many of the functions of Automobile City Fabric requiring large spaces (e.g. freight and industry) also need to be respected. However, there are many parts of Automobile City Fabric needing to be redeveloped and cities are seeking how Transit Urban Fabric can be built into these areas with dense, mixed centers built around stations as in the Rosslyn-Ballston corridor in Arlington, Virginia, also in Tysons Corner, Virginia, and along Vancouver's Skytrain at stations such as JoyceCollingwood and New Westminster. In our own town we have seen many more examples including station precincts around Perth's major rail expansion (Newman \& Kenworthy, 2015; Schiller \& Kenworthy, 2018; McIntosh et al., 2015). The revival of Perth's rail has been a personal struggle for us but has now become of global interest as the transit system grew ten times and seven new rail lines will complete a completion of a rail backbone to every corridor in the rapidly growing city with some of the transit urban fabric happening by market processes (Newman, 2021). Most US cities now seem to want more of this process, but not all are able to see how to do it. Perhaps the next thirty years may help (Glazebrook \& Newman, 2018).

\section{The Next Thirty Years}

The perspectives of the past thirty years may not work for the next thirty, especially as new technology for mobility is likely to be quite different to anything we have had before. There is a major change in energy from concern about oil scarcity driving our original research to a situation where oil is simply being replaced by electro-mobility in all its forms. Disruptive technologies abound and are multiplying in an unprecedented way across the whole transport field: burgeoning bike and car sharing schemes, e-scooters and other rapidly developing micro-mobility, Uber, Lyft and other similar Transportation Network Companies (TNC), new kinds of electric cars and trucks including hydrogen fuel cells, autonomous cars and more. All of these systems are going to have respond to climate change as well as the historic issues of automobile dependence (Newman, Beatley, \& Boyer, 2017).

Autonomous vehicles (AV's) providing "mobility as a service" (MaaS) are touted as transforming our cities (Dudson, 2017) as they are likely to be electric and much safer so this will eliminate many of the automobile's problems. However, the important lessons we have learnt are that cities are shaped always by the human limits related to their travel time budgets and the urban system is likely to adjust to whatever is provided in transport and land use to ensure that this travel time daily limit is maintained. This will shape our cities in the future as it has in 
the past.

The question is whether AV's are going to help solve such travel time issues as well as its claims of reduced pollution and safety improvements. The opportunities provided by AV's are its potential to be electric and to provide for transport demand without needing to own a car. Electric vehicles of all kinds will be needed without doubt to help solve the oil problem, but automobile dependence problems have always been about much more than oil. However, the same issues of automobile dependence as the past thirty years may exist depending on what kind of autonomous transport and what kind of urban fabric can be provided.

The purely automobile-based autonomous system will no doubt increase vehicle kilometers of travel (VKT) and urban sprawl will be given something of a boost if they save some time (though the history of transportation planning to save time has failed, rather, any time advantages have just been used to travel further). In any case, any possibility of time advantages will only happen if road capacity is increased to accommodate the increased VKT associated with demand-responsive vehicles looking for passengers. This is a major issue as the ability to increase road capacity further is very difficult politically if roads are used to obliterate large amounts of developed urban fabric or they will need to have tunnels built at huge expense.

Already it appears that Uber and Lyft are causing increases in VKT as they provide a better service than transit in some cities. TNCs such as Uber and Lyft combined with taxis are exceeding the total use of local bus services in the United States (Schaller, 2018). Schiller (2016) in turn provides a comprehensive and sobering review of the problems of unbridled use of AV's, which peels off some of the gloss and hype surrounding present discussions about them.

There will also be another problem. We would suggest that there will be strong reactions to excessive numbers of AV's in Walking City and Transit City Fabric where walkability is needed because they threaten to wind back the gains in livability in such areas, that were fought hard for by citizen groups and city governments over the last 30 years (Newman, 2019). Most areas will ban AV's from high quality walkable areas as they simply will not be able to move through heavily pedestrianized areas. If AV's are channelled down a main road at high speed with no distance between them (as suggested) they will form an impenetrable wall worse than most freeways. So perhaps AV's will only be useful in outer areas which are built around cars, i.e. automobile dependent suburbs. If AV's simply increased Automobile City Fabric on the fringe, this will rapidly reduce the ability to provide a better urban future as urban regeneration and transit investment are drained into urban sprawl as has now been shown over and over to be a serious issue. These are the same issues we faced 30 years ago but had begun to think we had seen a big change away from such automobile dependence.

There is another kind of autonomous transport that creates Transit Urban Fabric and which can still make the best opportunities of the smart technologies that enable vehicles to be guided: electric BRT, LRT and Trackless Trams. All three, 
now called mid-tier transit, are electric and have various levels of autonomous and guidance technology enabling them to run fast along main roads. This can significantly increase capacity (up to 6 lanes of car-based traffic) and with their innovations that prevent noise and emissions they can enable development around stations due to their ability to unlock land value (Newman, Hargroves et al., 2019a). Our research suggests that such a Transit City Fabric-building system can provide a much faster and more attractive ride quality along most corridors than bus-based systems, along old main roads that have lost their transit or new main roads needing a better system; especially will this work if done in partnership with private developers who can build innovative precincts around stations (Newman et al., 2019a; 2021). They can be used in combination with shared mobility shuttles and micro-mobility for last mile connectivity (Glazebrook \& Newman, 2018) and could in fact be financed through associated land development at stations (Newman, Davies-Slate, \& Jones, 2018; Davies-Slate \& Newman, 2018). They could be a key step in the transition to Net Zero Cities as each part of the transport and land development system can be electric and solar-based (Newman et al., 2021).

Such Transit-Activated Corridors, as we call them, would be greatly enhanced by a city governance system that created these systems of transit and density along main roads. Such corridors would be turned into urban boulevards by closely coordinated governance via planning and transit agencies, rather than through the longstanding traffic engineering practices of traditional road agencies. This is being done in European cities using Sustainable Urban Mobility Plans (Eltis, 2016). The extent of these changes will depend as always, on the politics of how much automobile dependence is wanted over transit, walkability and dense urbanism.

\section{Conclusion}

The city of the next thirty years is likely to have new technologies not even thought about today, but it is likely to need us to make choices similar to the ones we discovered as being needed thirty years ago:

1) Reorienting transport priorities away from automobiles. Cities will need to work out how to gain the best outcome from all the new transport technologies and smartphone-based mobility management systems that are appearing. But most importantly, we will still need to be vigilant to keep reorienting transport priorities towards transit, walking and cycling to enable more common good outcomes with walkable centers linked into corridors anchored by fast transit.

2) Re-urbanizing our cities instead of scattering them outwards. Perhaps we will learn to significantly reduce travel after the Covid pandemic has shown us how to do technologically improved face-to-face meetings. And we will have nearby relocalized centres that also have come into their own during the pandemic shutdown, probably through the use of Transit Activated Corridors using high quality mid-tier transit. 
3) Globally we will need, in the next 30 years, to have removed all fossil fuels whilst providing livable, productive, sustainable and equitable outcomes. Probably this will mean we will need to reurbanize and reorient transport priorities even more than we have done in the past 30 years. As set out in the paper, there will need to be new approaches to achieving the full data-sets required as well as new tools to enable these solutions to be delivered.

\section{Conflicts of Interest}

The authors declare no conflicts of interest regarding the publication of this paper.

\section{References}

ADB (2019). Presentation by Jamie Leather, Chief of Transport Sector Group, Asian Development Bank. Twelfth Intergovernmental Regional Environmentally Sustainable Transport (EST) Forum in Asia, Hanoi, 28-31 October 2019.

BITRE (2016). Lengthy Commutes in Australia. Bureau of Transport, Industry and Resource Economics, Report 144, Government of Australia, Canberra.

Buehler, R., Pucher, J., \& Bauman, A. (2020). Physical Activity from Walking and Cycling for Daily Travel in the United States, 2001-2017: Demographic, Socioeconomic, and Geographic Variation. Journal of Transport and Health, 16, Article ID: 100811. https://doi.org/10.1016/j.jth.2019.100811

Bullen, P. (2009). Residential Regeneration and Adaptive Reuse: Learning from the Experiences of Los Angeles. Structural Survey, 27, 351-360. https://doi.org/10.1108/02630800911002611

Burd, C., Burrows, M., \& McKenzie, B. (2021). Travel Time to Work in the United States: 2019. American Community Survey Reports, United States Census Bureau.

Calthorpe, P. (1993). The Next American Metropolis Ecology, Community, and the American Dream. Princeton Architectural Press.

Cox, W., \& Pavletich, H. (2020). 16th Annual Demographia International Housing Affordability Survey. Demographia. http://demographia.com/dhi.pdf

Curl, J. S. (2018). Making Dystopia: The Strange Rise and Survival of Architectural Barbarism. Oxford University Press.

Darchen, S. (2016). Regeneration and Networks in the Arts District (Los Angeles): Rethinking Governance Models in the Production of Urbanity. Urban Studies, 54, 36153635. https://doi.org/10.1177/0042098016669917

Davies-Slate, S., \& Newman, P. (2018). Partnerships for Private Transit Investment: The History and Practice of Private Transit Infrastructure with a Case Study in Perth, Australia. Urban Science, 2, 84-104. https://doi.org/10.20944/preprints201807.0466.v1

Duany, A., Speck, J., \& Lydon, M. (2009). The Smart Growth Manual. McGraw-Hill Professional.

Duany, A., Plater-Zyberk, E., \& Speck, J. (2001). Suburban Nation: The Rise of Sprawl and the Decline of the American Dream. North Point Press.

Dudson, B. (2017). Intelligent Vehicles and Cities. Technical Report. https://www.researchgate.net/publication/316009618 Intelligent Vehicles and Cities

Elks, S. (2019). E-Transport Boom Could See First Major European City Go Car Free in 2020 . 
http://www.thisisplace.org/i/?id=f7723326-d401-473d-b41d-dd18827a6340\&utm sourc $\underline{\mathrm{e}=\text { Newsletter\&utm medium=Email\&utm campaign=Place }}$

Eltis: The Urban Mobility Observatory (2016). Guidelines for Sustainable Urban Mobility Plans. European Commission's Directorate General for Mobility and Transport.

Ewing, R., \& Cervero, R. (2017). Does Compact Development Make People Drive Less? The Answer Is Yes. Journal of the American Planning Association, 83, 19-25. https://doi.org/10.1080/01944363.2016.1245112

Ewing, R., \& Hamidi, S. (2017). Costs of Sprawl. Taylor and Francisk. https://doi.org/10.4324/9781315628103

Ewing, R., Hamidi, S., Tian, G., Proffitt, D., Tonin, S., \& Fregolent, L. (2017). Testing Newman and Kenworthy's Theory of Density and Automobile Dependence, Journal of Planning Education and Research, 2, 1-17. https://doi.org/10.1177/0739456X16688767

Florida, R. (2010). The Great Reset: How New Ways of Living and Working Drive PostCrash Prosperity. Random House.

Florida, R. (2012a). Cities with Denser Cores Do Better. The Atlantic Website. http://www.theatlanticcities.com/jobs-and-economy/2012/11/cities-denser-cores-do-be $\underline{\text { tter/3911 }}$

Florida, R. (2012b). The Rise of the Creative Class: Revisited. Basic Books.

Florida, R. (2012c). How and Why American Cities Are Coming Back. http://www.theatlanticcities.com/jobs-and-economy/2012/05/how-and-why-americancities-are-coming-back/2015

Florida, R. (2018). The New Urban Crisis. How Our Cities Are Increasing Inequality, Deepening Segregation, and Failing the Middle Class and What We Can Do about It. Basic Books.

Gao, Y., \& Kenworthy, J. (2017). Chapter 3. China. In D. Pojani, \& D. Stead (Eds.), The Urban Transport Crisis in Emerging Economies (pp. 33-58). Springer Nature. https://doi.org/10.1007/978-3-319-43851-1 3

Gao, Y., \& Newman, P. (2018). Beijing's Peak Car Transition: Hope for Emerging Cities in the $1.5^{\circ} \mathrm{C}$ Agenda. Urban Planning, 3, 82-93. https://doi.org/10.17645/up.v3i2.1246

Gao, Y., Kenworthy, J. R., Newman, P., \& Gao, W. (2018). Chapter 2.2. Transport and Mobility Trends in Beijing and Shanghai: Implications for Urban Passenger Transport Energy Transitions Worldwide. In P. Droege (Ed.), Urban Energy Transition: Renewable Strategies for Cities and Regions (2nd ed., pp. 205-224). Elsevier. https://doi.org/10.1016/B978-0-08-102074-6.00025-5

Gao, Y., Newman, P., \& Kenworthy J. (2020). Are Beijing and Shanghai Automobile Dependent Cities? In Handbook on Transport and Urban Transformation in China, Edward Elgar. https://doi.org/10.4337/9781786439246.00021

Gaynor, A., Newman, P., \& Jennings, P. (Eds.) (2017). Never Again: Reflections on Environmental Responsibility after Roe 8. UWA Scholar Press.

Gehl, J. (2010). Cities for People. Island Press.

Glaeser, E. (2011). The Triumph of the City: How Our Greatest Invention Makes Us Richer, Smarter, Greener, Healthier and Happier. Penguin Press.

Glazebrook, G., \& Newman, P. (2018). The City of the Future. Urban Planning, 3, 1-20. https://doi.org/10.17645/up.v3i2.1247

Gomez-Ibanez, J. (1991). A Global View of Automobile Dependence. Journal of American Planning Association, 57, 376-379. https://doi.org/10.1080/01944369108975464 
Gordon, P., \& Richardson, H. (1989). Gasoline Consumption and Cities: A Reply. Journal of American Planning Association, 55, 342-346. https://doi.org/10.1080/01944368908975421

Handy, S. (2002). Smart Growth and the Transportation-Land Use Connection: What Does the Research Tell Us? International Regional Science Review, 28, 146-167. https://doi.org/10.1177/0160017604273626

Handy, S., Boarnet, M., Ewing, R., \& Killingsworth, R. (2002). How the Built Environment Affects Physical Activity: Views from Urban Planning. American Journal of Preventive Medicine, 23, 64-73. https://doi.org/10.1016/S0749-3797(02)00475-0

Houghton, G., \& Hunter, C. (1994). Sustainable Cities. Regional Studies Association, Kingsley Publishers.

Kane, M. P. (2010). Devising Public Transport Systems for Twenty-First Century Economically Productive Cities-The Proposed Knowledge Ring for Perth. Australian Planner, 47, 75-84. https://doi.org/10.1080/07293681003767777

Kenworthy, J. (2013). Decoupling Urban Car Use and Metropolitan GDP Growth. World Transport Policy and Practice, 19, 7-21.

Kenworthy, J., \& Laube, F. (2001). The Millennium Cities Database for Sustainable Transport. CDROM Database. International Union Association of Public Transport, (UITP) and Institute for Sustainability and Technology Policy (ISTP).

Kenworthy, J., Laube, F, Newman, P., \& Barter, P. (1997). Indicators of Transport Efficiency in 37 Global Cities. A Report for the World Bank, Institute for Science and Technology Policy, Murdoch University.

Kenworthy, J. R. (2017a). Chapter 3. The Good, the Bad and the Ugly in Urban Transport: Comparing Global Cities for Dependence on the Automobile. In J. Hartz-Karp, \& D. Marinova (Eds.), Methods for Sustainability Research (pp. 46-62). Edward Elgar Publishing. https://doi.org/10.4337/9781786432735.00012

Kenworthy, J. R. (2017b). Is Automobile Dependence in Emerging Cities an Irresistible Force? Perspectives from São Paulo, Taipei, Prague, Mumbai, Shanghai, Beijing and Guangzhou. Sustainability, 9, 1953. https://doi.org/10.3390/su9111953

Kooshian, C., \& Winkelman, S. (2011). Recent Trends in the Travel Intensity of the US Economy. Center for Clean Air Policy. http://wstlur.org/symposium/2011/agenda/documents/presentations/2-kooshian.pdf

Leinberger, C. B. (2007). The Option of Urbanism: Investing in the New American Dream. Island Press.

Leinberger, C. B., \& Lynch, P. (2014). Foot Traffic Ahead: Ranking Walkable Urbanism in Americas Largest Metros. George Washington University School of Business, Center for Real Estate and Urban Analysis.

Marchetti, C. (1994). Anthropological Invariants in Travel Behaviour. Technical Forecasting and Social Change, 47, 75-78. https://doi.org/10.1016/0040-1625(94)90041-8

Matan, A., \& Newman, P. (2016). People Cities. The Life and Legacy of Jan Gehl. Island Press. https://doi.org/10.4135/9781473983243.n16

McIntosh, J., Newman, P., Trubka, R., \& Kenworthy, J. (2015). Framework for Land Value Capture from the Investment in Transit in Car Dependent Cities. Journal of Transport and Land Use, 10, 1-31. http://jtlu.org https://doi.org/10.5198/jtlu.2015.531

McIntosh, J., Trubka, R., Kenworthy, J., \& Newman, P. (2014). The Role of Urban Form and Transit in City Car Dependence: Analysis of 26 Global Cities from 1960 to 2000. 
Transportation Research Part D: Transport and Environment, 33, 95-110. https://doi.org/10.1016/j.trd.2014.08.013

Morrow, R. (2019). Cars: Accelerating the Modern World Review-Revolutions behind the Wheel. The Observer, 24th November.

National Trust for Historic Preservation (2016). A Tale of Two Planners: Jane Jacobs vs. Robert Moses.

https://savingplaces.org/stories/a-tale-of-two-planners-jane-jacobs-and-robert-moses\#. $\underline{\mathrm{XeqH} H \mathrm{H} 2 \mathrm{ZOgA}}$

Newman, P. (2017) Planning Ethics and Urban Density: Overcoming Fear in Anglo Saxon cities. In J. H. P. Bay, \& S. Lehmann (eds.), Growing Compact: Urban Form, Density and Sustainability, Routledge.

Newman, P. (2021). The Perth Rail Revival (1979-2019). Australian Railway History, August, 16-25.

Newman, P., Davies-Slate, S., Conley, D., Hargroves, K., \& Mouritz, M. (2021). From TOD to TAC: Why and How Transport and Urban Policy Needs to Shift to Regenerating Main Road Corridors with New Transit Systems. Urban Science, 5, 52. https://doi.org/10.3390/urbansci5030052

Newman, P. (2019). Driverless Vehicles and Pedestrians Don't Mix. So How Do We ReArrange Our Cities? The Conversation, November 28.

https://theconversation.com/driverless-vehicles-and-pedestrians-dont-mix-so-how-dowe-re-arrange-our-cities-126111

Newman, P., \& Kenworthy J. (2015). The End of Automobile Dependence: How Cities Are Moving beyond Car-Based Planning. Island Press.

https://doi.org/10.5822/978-1-61091-613-4

Newman, P., \& Kenworthy, J. (1988). The Transport Energy Trade Off: Fuel-Efficient Traffic versus Fuel-Efficient Cities. Transportation Research, 22, 163-174. https://doi.org/10.1016/0191-2607(88)90034-9

Newman, P., \& Kenworthy, J. (1989a). Gasoline Consumption and Cities: A Comparison of US Cities with a Global Survey and Its Implications. Journal of American Planning Association, 55, 24-37. https://doi.org/10.1080/01944368908975398

Newman, P., \& Kenworthy, J. (1989b). Cities and Automobile Dependence: An International Sourcebook. Gower Technical.

Newman, P., \& Kenworthy, J. (1999). Sustainability and Cities: Overcoming Automobile Dependence. Island Press.

Newman, P., Kenworthy, J., \& Glazebrook, G. (2013). Peak Car and the Rise and Rise of Global Rail: Why This Is Happening and What It Means for Large and Small Cities. Journal of Transportation Technologies, 3, 272-287. https://doi.org/10.4236/jtts.2013.34029

Newman, P., \& Kenworthy, J. (2011). "Peak Car Use": Understanding the Demise of Automobile Dependence. World Transport Policy and Practice, 17, 31-42.

Newman, P., Kosonen, L., \& Kenworthy, J. (2016). Theory of Urban Fabrics: Planning the Walking, Transit/Public Transport and Automobile/Motor Car Cities for Reduced Car Dependency. Town Planning Review, 87, 429-458. https://doi.org/10.3828/tpr.2016.28

Newman, P., Beatley, T., \& Boyer, H. (2017). Resilient Cities. Overcoming Fossil Fuel Dependence. Island Press. https://doi.org/10.5822/978-1-61091-686-8 
Newman, P., Davies-Slate, S., \& Jones, E. (2018). The Entrepreneur Rail Model: Funding Urban Rail through Majority Private Investment in Urban Regeneration. Research in Transportation Economics, 67, 19-28. https://doi.org/10.1016/j.retrec.2017.04.005

Newman, P., Hargroves, K., Davies-Slate, S., Conley, D., Verschuer, M., Mouritz, M., \& Yangka, D. J. (2019a). The Trackless Tram: Is It the Transit and City Shaping Catalyst We Have Been Waiting for? Journal of Transportation Technologies, 9, 31-55.

https://doi.org/10.4236/jtts.2019.91003

Newman, P., Mouritz, M., Verschuer. M., Davies-Slate, S., Caldera, S., Desha, C., \& Reid, S. (2019b). Trackless Trams and Australian Urban Fabric. State of Australian Cities Conference, Perth.

Puentes, R., \& Tomer, A. (2009). The Road Less Travelled: An Analysis of Vehicle Miles Travelled Trends. The U.S. Metropolitan Infrastructure Initiative Series, Brookings Institute.

Schaller, B. (2018). The New Automobility: Lyft, Uber and the Future of American Cities. Schaller Consulting.

Schiller, P. (2016). Automated and Connected Vehicles: Hype or Hope. World Transport Policy and Practice, 22, 28-44.

Schiller, P., \& Kenworthy, J. R. (2018). An Introduction to Sustainable Transportation: Policy, Planning and Implementation (2nd ed.). Earthscan. https://doi.org/10.4324/9781315644486

Sharma, R., \& Newman, P. (2020). Land Value Capture Tools: Integrating Transit and Land Use through Finance to Enable Economic Value Creation. Modern Economy, 11, 938964. https://doi.org/10.4236/me.2020.114070

Sharma, R., \& Newman, P. (2018). Does Rail Increase Land Value in Emerging Cities? Value Uplift from Bangalore Metro. Transport Research A: Policy and Practice, 117, 1016. https://doi.org/10.1016/j.tra.2018.08.020

Shoup, D. (2005). The High Cost of Free Parking. APA Planners Press.

Sloane, D. C. (2017). Planning Los Angeles. Routledge. https://doi.org/10.4324/9781351179157

Steuteville, R. (2019). “Car-Free” Development Breaks Ground in Arizona. Public Square (A CNU Journal), December 16, 2019.

https://www.cnu.org/publicsquare/2019/12/16/car-free-development-breaks-ground-ar izona

Thomson, G., \& Newman, P. (2018). Urban Fabrics and Urban Metabolism-From Sustainable to Regenerative Cities. Resources, Conservation and Recycling, 132, 218-229. https://doi.org/10.1016/j.resconrec.2017.01.010

Trubka, R., Newman, P., \& Bilsborough, D. (2010a). Costs of Urban Sprawl (1). Infrastructure and Transport. Environment Design Guide, 83, 1-6.

Trubka, R., Newman, P., \& Bilsborough, D. (2010b). Costs of Urban Sprawl (2). Greenhouse Gases. Environment Design Guide, 84, 1-16.

Trubka, R., Newman, P., \& Bilsborough, D. (2010c). Costs of Urban Sprawl (3). Physical Activity Links to Healthcare Costs and Productivity. Environment Design Guide, 85, 1 13.

Wachs, M., \& Crawford, M. (1991). The Car and the City: The Automobile, the Built Environment and Daily Life. University of Michigan Press. 